\title{
The Effect of Hydroxyl Groups in the Aglycone in the Solvolysis of Glucopyranosides by Trifluoroacetolysis
}

\author{
LARS-ERIK FRANZÉN and SIGFRID SVENSSON
}

Department of Clinical Chemistry, University Hospital, S-221 85 Lund, Sweden

\begin{abstract}
2,3,4,6-Tetra- $O$-methyl- $\beta$-D-glucosides and 2,3,4-tri$O$-methyl- $\beta$-D-glucosides having hydroxyl groups in the aglycone moiety have been synthesized. The compounds have been investigated for their stability towards trifluoroacetolysis in order to evaluate the stabilizing effect of hydroxyl groups in the aglycone on solvolysis of the glycosidic bond. It was found that a hydroxyl group in the $\beta$-or $\gamma$-position to the glycosidic oxygen exerts little effect in retarding the solvolysis of the glycosidic bond. However, two hydroxyl groups in the $\beta$-position showed a moderate effect in diminishing the rate of solvolysis.
\end{abstract}

A reaction, trifluoroacetolysis, has been introduced which can be used for structural studies of the carbohydrate portion of glycoconjugates. Methods have been developed for $\mathrm{N}$-deacetylation of glycosidically linked 2-acetamido-2-deoxy-sugars, ${ }^{1}$ specific degradation of 2-acetamido-2-deoxy-sugars at the reducing end of oligosaccharides, ${ }^{2-5}$ isolation of $\mathrm{N}$ - and $\mathrm{O}$-glycosidically linked carbohydrate chains in glycoproteins, ${ }^{3-5}$ and specific cleavage of the glycosidic bond to ceramide in glycolipids. ${ }^{6}$ These methods are feasible because the hydroxyl groups of carbohydrates are rapidly trifluoroacetylated during trifluoroacetolysis and the electron-with-drawing effect of the $O$-trifluoroacetyl groups prevents solvolysis of glycosides ${ }^{7}$ and acid catalyzed degradation of reducing sugars. ${ }^{2}$ In recent studies $^{8,9}$ on trifluoroacetolysis of partially methylated methyl $\alpha$-D-gluco- and xylopyranosides, the effect of $O$-trifluoroacetyl groups in various positions in inhibitions of solvolysis was evaluated. We now report a study on the stabilizing effects of hydroxyl groups in the aglycone part of oligosaccharides with the aid of synthesized model compounds.

\section{RESULTS AND DISCUSSION}

The compounds 2-hydroxyethyl 2,3,4,6-tetra- $O$ methyl- $\beta$-D-glucoside (1), 1-O-(2,3,4,6-tetra- $O$-methyl- $\beta$-D-glucosyl)-D,L-glycerol (2), 2-O-(2,3,4,6-tetra- $O$ methyl- $\beta$-D-glucosyl)-glycerol (3), 1-O-(2,3,4,6-tetra$O$-methyl- $\beta$-D-glucosyl)-2- $O$-methyl-D,L-glycerol (4), 2-hydroxyethyl 2,3,4-tri- $O$-methyl- $\beta$-D-glucoside (5), and $2-O-(2,3,4$-tri- $O$-methyl- $\beta$-D-glucosyl)-glycerol (6) have been synthesized using conventional techniques. Compounds 2 and 4 were synthesized by coupling 2,3,4,6-tetra- $O$-acetyl- $\alpha$-D-glucosyl bromide to $\mathrm{D}, \mathrm{L}-1,2-O$-isopropylidene-glycerol yielding $1-O$ $(2,3,4,6$-tetra- $O$-acetyl- $\beta$-D-glucosyl)-2,3- $O$-isopropylidene-D,L-glycerol as an intermediate. The two diastereoisomers of this compound were not separated, and thus compounds 2 and 4 were obtained as diastereoisomeric mixtures.

Mass spectrometry of compounds 1-6 as their peracetylated derivatives. The mass spectra of the peracetylated compounds $1-6$ all show strong
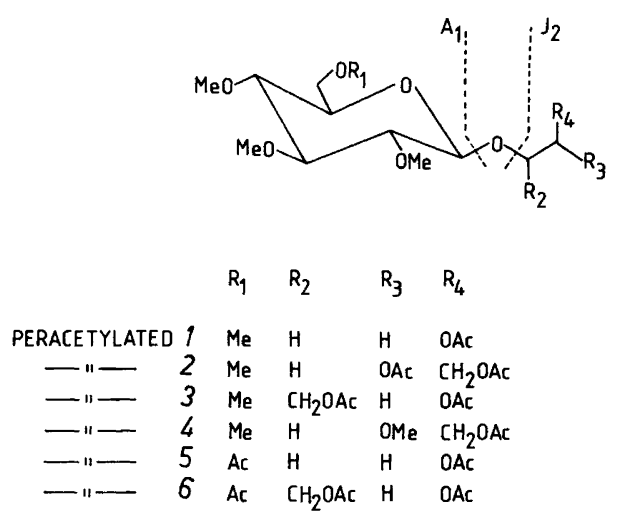

Scheme 1. 


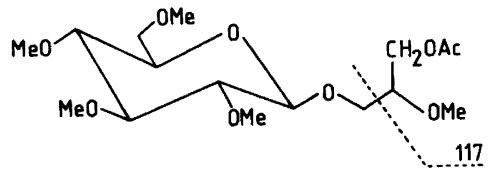

Scheme 2.

fragments in the $\mathrm{J}$-series ${ }^{10}$ which allow calculation of the molecular weight of the aglycone units (Scheme 1). Thus peracetylated compounds 1 and 5 give ions with $m / e 147\left(\mathrm{~J}_{1}\right)$ and $m / e 87\left(\mathrm{~J}_{2}\right)$, compounds 2,3 , and 6 ions with $m / e 219\left(\mathrm{~J}_{1}\right)$ and $m / e 159$ $\left(\mathrm{J}_{2}\right)$, and compound 4 ions with $\mathrm{m} / \mathrm{e} 191\left(\mathrm{~J}_{1}\right)$ and $m / e 131\left(\mathrm{~J}_{2}\right)$.

The aglycone unit is further characterized, in peracetylated compound 4 , by a fragment at $m / e 117$ obtained by $\alpha$-cleavage at the methoxyl group (Scheme 2).

A weak but recognizable A-series ${ }^{10}$ of fragments (Scheme 1) gives ions at $m / e 187\left(\mathrm{~A}_{2}\right)$ and $m / e 155$ $\left(\mathrm{A}_{3}\right)$ for peracetylated $1-4$ and at $m / e 215\left(\mathrm{~A}_{2}\right)$ and $m / e 155\left(A_{3}\right)$ for peracetylated 5 and 6 .

Trifluoroacetolysis of compounds $1-6$ and the corresponding methyl $\beta$-D-glucosides. These compounds together with stable internal standards were treated with trifluoroacetic acid (TFA) and trifluoroacetic anhydride (TFAA) in the proportions $1: 1,1: 4$, and $1: 50(\mathrm{v} / \mathrm{v})$ at various temperatures for $48 \mathrm{~h}$. Each reaction mixture was de-O-trifluoroacetylated, reduced, acetylated, and analyzed qualitatively and quantitatively by GLC-MS. The results are shown in Tables 1 and 2 .

Methyl 2,3,4,6-tetra- $O$-methyl- $\beta$-D-glucoside and the compounds $1-4$ were completely solvolyzed

Table 1. Trifluoroacetolysis of methyl 2,3,4,6-tetra$O$-methyl- $\beta$-D-glucoside (Me 2,3,4,6-OMe-Glc) and compounds $1-4$ in TFA-TFAA (1:1 and 1:50) at $60{ }^{\circ} \mathrm{C}$ for $48 \mathrm{~h}$.

\begin{tabular}{lcc}
\hline \multirow{2}{*}{ Compound } & \multicolumn{2}{c}{ Recovery $/ \mathrm{mol}^{\mathrm{a}}{ }^{\mathrm{a}}$} \\
\cline { 2 - 3 } & $1: 1$ & $1: 50$ \\
\hline Me 2,3,4,6-OMe-Glc & 6 & 46 \\
1 & 4 & 77 \\
2 & 22 & 85 \\
3 & 30 & 93 \\
4 & 5 & 74 \\
\hline
\end{tabular}

${ }^{a}$ Determined after de- $O$-trifluoroacetylation, reduction $\left(\mathrm{NaBD}_{4}\right)$ and acetylation.
Table 2. Trifluoroacetolysis of methyl 2,3,4-tri- $O$ methyl- $\beta$-D-glucoside (Me 2,3,4-OMe-Glc) and compounds 5 and 6 in TFA - TFAA $(1: 1,1: 4$, and $1: 50)$ at $100{ }^{\circ} \mathrm{C}$ for $48 \mathrm{~h}$.

\begin{tabular}{lccl}
\hline \multirow{2}{*}{ Compound } & \multicolumn{3}{l}{ Recovery/mol $\%^{a}$} \\
\cline { 2 - 4 } & $1: 1$ & $1: 4$ & $1: 50$ \\
\hline Me 2,3,4-OMe-Glc & - & $4(20)^{b}$ & $47(36)$ \\
5 & - & 6 & 59 \\
6 & 1 & 24 & 80 \\
\hline
\end{tabular}

${ }^{a}$ Determined after de- $O$-trifluoroacetylation, reduction $\left(\mathrm{NaBD}_{4}\right)$, and acetylation. ${ }^{b}$ Values in parenthesis represent anomerized product.

with TFA/TFAA in the proportions 1:1 and 1:50 at $100{ }^{\circ} \mathrm{C}$ for $48 \mathrm{~h}$. The trifluoroacetylated 2,3,4,6-tetra$O$-methyl-D-glucose formed by the solvolysis reaction was then further destroyed by acid catalyzed elimination reactions. At $60^{\circ} \mathrm{C}$ (Table 1), however, about half of the amount of methyl 2,3,4,6-tetra-Omethyl- $\beta$-D-glucoside could be recovered after trifluoroacetolysis using TFA/TFAA in the proportions 1:50. Compound 1 which has a hydroxyl group in the aglycone in $\beta$-position to the exocyclic glycosidic oxygen was more stable and could be recovered in $77 \%$ yield after trifluoroacetolysis in TFA/TFAA 1:50. Similar results were obtained for compound 4 which has a hydroxyl group in the $\gamma$-position. With hydroxyl groups in the $\beta$ - and $\gamma$-position (2) the stability was somewhat greater and with two hydroxyl groups in the $\beta$-position (3) almost complete stability in TFA/TFAA 1:50 was obtained. In TFA/TFAA 1:1 the compounds 2 and 3 were noticeably more stable than compounds 1,4 , and methyl $2,3,4,6$-tetra- $O$-methyl- $\beta$-D-glycoside.

Since solvolysis by TFA/TFAA is initiated by oxonium ion formation of either the ring oxygen or the exocyclic glycosidic oxygen and since in compounds $1-4$ no electron-withdrawing $O$-trifluoroacetyl group is protecting the ring oxygen from forming such an ion, the small stabilizing effect exerted by the $O$-trifluoroacetyl groups in the aglycone could be due to preferential oxonium ion formation of the ring oxygen.

In order to investigate if the protective action of $O$-trifluoroacetyl groups in the aglycone was larger if ionization of the ring oxygen was hindered, the compounds 5 and 6 with a 6-hydroxyl group were prepared and their solvolysis in TFA/TFAA was compared with methyl 2,3,4-tri- $O$-methyl- $\beta$-D-glu- 
coside. The results (Table 2) show that one or two hydroxyl groups in the $\beta$-position prevented solvolysis to about the same extent as the hydroxyl groups in the model compounds 1 and 3 as compared with the corresponding methyl $\beta$-D-glucosides. The results presented in this study show that hydroxyl groups in the aglycone have an effect in preventing solvolysis of glycosides in TFA/TFAA. However, the effect was small. The effect should nevertheless be important for stabilizing labile sugar residues in oligo- and polysaccharides especially when 3-linked to another sugar unit.

\section{EXPERIMENTAL}

General methods. GLC was carried out on a Perkin-Elmer 3920 gas chromatograph equipped with a flame ionization detector. Separations were performed on an SE-30 W.C.O.T. glass capillary column $(25 \mathrm{~m} \times 0.25 \mathrm{~mm})$ at $200{ }^{\circ} \mathrm{C}$. GLC-MS was performed on a Varian MAT 311A instrument fitted with the above column. The spectra were recorded at $70 \mathrm{eV}$ with an ionization current of $3 \mathrm{~mA}$ and an ion source temperature of $120{ }^{\circ} \mathrm{C}$. The spectra were processed on an on-line computer system (Spectrosystem 100, Varian MAT). Silica gel column chromatography was carried out using the following solvent systems: (a) ethyl acetatelight petroleum, 1:1 (v/v); (b) ethyl acetate containing 3\% methanol; (c) ethyl acetate containing $8 \%$ methanol; (d) ethyl acetate containing $15 \%$ methanol; (e) ethyl acetate; and (f) ethyl acetate light petroleum, 2:3 (v/v). Reactions and separations were monitored by thin layer chromatography (TLC) on silica gel plates.

2-Hydroxyethyl 2,3,4,6-tetra-O-methyl- $\beta$-D-glucoside (1). 1 was obtained from 2-hydroxyethyl $2,3,4,6$-tetra- $O$-acetyl- $\beta$-D-glucoside ${ }^{11,12}$ by (a) tritylation, (b) de-O-acetylation, (c) methylation, and (d) detritylation.

(a) Tritylation. 2-Hydroxyethyl 2,3,4,6-tetra-Oacetyl- $\beta$-D-glucoside $(1.6 \mathrm{~g})$ and chlorotriphenylmethane $(1.6 \mathrm{~g})$ were added to $20 \mathrm{ml}$ of pyridine and the mixture was left at room temperature for $48 \mathrm{~h}$. The reaction mixture was thereafter partitioned between water $(50 \mathrm{ml})$ and chloroform $(50 \mathrm{ml})$. The chloroform layer was washed with ice-cold aqueous potassium hydrogen sulfate, aqueous sodium carbonate and water. After drying the chloroform layer over anhydrous sodium sulfate it was evaporated to dryness. The residue was crystallized from absolute ethanol. The crude product ( $2.1 \mathrm{~g})$ was used in the next step without further purification.

(b) De-O-acetylation. 2-O-Trityloxyethyl 2,3,4,6tetra-O-acetyl- $\beta$-D-glucoside ( $1.2 \mathrm{~g}$ ) (above) was dissolved in $1 \mathrm{M}$ ammonia in methanol-water (4:1, $\mathrm{v} / \mathrm{v}, 50 \mathrm{ml}$ ). After $24 \mathrm{~h}$ at room temperature the reaction mixture was evaporated to dryness. The yield of crude amorphous 2-O-trityloxyethyl $\beta$-Dglucopyranoside was $0.9 \mathrm{~g}$. The product was homogeneous on TLC (solvent e).

( ) Methylation. 2-O-Trityloxyethyl $\beta$-D-glucopyranoside (above) $(600 \mathrm{mg}$ ) was methylated with sodium methylsulfinylmethanide - methyl iodide in dimethyl sulfoxide according to the procedure of Hakomori. ${ }^{13}$ The methylated product was purified by chromatography on a silica gel column eluted with solvent a. The yield of purified 2-O-trityloxyethyl 2,3,4,6-tetra- $O$-methyl- $\beta$-D-glucoside was 620 $\mathrm{mg}$.

(d) Detritylation. 2-O-Trityloxyethyl 2,3,4,6-tetra$O$-methyl- $\beta$-D-glucoside (600 mg) (above) was detritylated by treatment with $0.2 \mathrm{M}$ hydrochloric acid in methanol $(50 \mathrm{ml})$ at room temperature for $18 \mathrm{~h}$. The reaction mixture was neutralized $\left(\mathrm{Ag}_{2} \mathrm{CO}_{3}\right)$, filtered and evaporated to dryness. The crude product was purified twice by chromatography on a silica gel column eluted with solvent $b$. The yeild of 1 as a chromatographically pure syrup was $240 \mathrm{mg}$. Part of 1 was acetylated and analyzed by GLC-MS. It gave a single peak with a mass spectrum containing ions at $m / e 43(60), 45(42), 71$ (22), $73(18), 75(15), 87(88), 88(100), 89(11), 101$ (68), 102 (7), $111(3), 127$ (4), 147 (22), 155 (2), 187 (4), and $221(2)$.

1-O-(2,3,4,6-Tetra-O-methyl- $\beta$-D-glucosyl)-D,Lglycerol ( 2$)$. 2 was obtained from $1-O-(2,3,4,6$-tetra$O$-acetyl- $\beta$-D-glucosyl)-2,3- $O$-isopropylidene-D,Lglycerol $^{12,14}$ by (a) de- $O$-acetylation, (b) methylation, and (c) removal of the isopropylidene group.

(a) De-O-acetylation. 1-O-(2,3,4,6-Tetra- $O$-acetyl$\beta$-D-glucosyl)-2,3-O-isopropylidene-D,L-glycerol (1.8 g) was de- $O$-acetylated as previously described in the preparation of 1 . The yield of crude $1-O-(\beta-\mathrm{D}-$ glucopyranosyl)-2,3- $O$-isopropylidene-D,L-glycerol was $1.2 \mathrm{~g}$. The product was homogeneous on TLC (solvent e).

(b) Methylation. 1-O-( $\beta$-D-Glucopyranosyl)2,3-Oisopropylidene-D, L-glycerol $(1.0 \mathrm{~g})$ was methylated as previously described. ${ }^{13}$ The crude product was purified twice by chromatography on a silica gel column eluted with solvent $e$. The yield of chromatographically pure $1-O-(2,3,4,6$-tetra- $O$-methyl- $\beta$-Dglycosyl)-2,3-O-isopropylidene-D,L-glycerol was 0.9 g. A single spot was seen on TLC (solvent e).

(c) (c) Removal of the isopropylidene group. 1-O$(2,3,4,6$-Tetra- $O$-methyl- $\beta$-D-glycosyl)-2,3- $O$-isopropylidene-D,L-glycerol $(800 \mathrm{mg}$ ) (above) was treated with $0.5 \mathrm{M}$ hydrochloric acid in methanol $(40 \mathrm{ml})$ at room temperature for $24 \mathrm{~h}$. After this time no starting material remained and a new single spot was seen on TLC (solvent c). The reaction mixture was neutralized $\left(\mathrm{Ag}_{2} \mathrm{SO}_{3}\right)$, filtered and evaporated to dryness. The crude product was 
purified by chromatography on a silica gel column eluted with solvent $c$. The chromatographically pure product was obtained as a syrup. The yield of 2 was $610 \mathrm{mg}$. Part of 2 was acetylated and analyzed by GLC-MS. This analysis showed two peaks in the ratio $2: 3$. Both components gave the same mass spectrum with ions at $m / e 43$ (52), 45 (22), $71(10), 73(7), 75(12), 88(100), 89(9), 101(52), 102(8)$, $111(2), 127(3), 145(3), 159(50), 187(1)$, and 219 (7). The appearance of two peaks after GLC-MS is expected since it should be a diastereoisomeric mixture. In order to exclude the possibility of an anomeric mixture, 2 was analysed by ${ }^{1} \mathrm{H}$ NMR. This spectrum showed only one doublet $(\delta 4.34 ; J, 10 \mathrm{~Hz})$ in the region of anomeric protons demonstrating that 2 contains only $\beta$-anomers.

2-O-(2,3,4,6-Tetra-O-methyl- $\beta$-D-glucosyl)-glycerol (3). 3 was obtained from 2-O-(2,3,4,6-tetra-Oacetyl- $\beta$-D-glycosyl)-1,3- $O$-benzylidene-glycerol ${ }^{12,15}$ by (a) de-O-acetylation, (b) methylation and (c) removal of the $O$-benzylidene group.

(a) De-O-acetylation. 2-O-(2,3,4,6-Tetra-O-acetyl$\beta$-D-glucosyl)-1,3-O-benzylidene-glycerol (1.6 g) was de- $O$-acetylated as previously described in the preparation 1 and 2 . The yield of crude $2-O-(\beta$-Dglucopyranosyl)-1,3- $O$-benzylidene-glycerol was 1.1 g. The product was homogeneous on TLC (solvent e).

(b) Methylation. 2-O-( $\beta$-D-Glucopyranosyl)-1,3-Obenzylidene-glycerol $(600 \mathrm{mg})$ was methylated as previously described. ${ }^{13}$ The crude product was purified twice by chromatography on a silica gel column eluted with solvent e. The yield of a chromatographically pure syrup was $650 \mathrm{mg}$.

(c) Removal of the O-benzylidene group. 2-O(2,3,4,6-Tetra- $O$-methyl- $\beta$-D-glucosyl)-1,3- $O$-benzylidene-glycerol $(400 \mathrm{mg}$ ) (above) was treated at room temperature with $0.5 \mathrm{M}$ hydrochloric acid in methanol $(40 \mathrm{ml})$ for $24 \mathrm{~h}$. After neutralization $\left(\mathrm{Ag}_{2} \mathrm{CO}_{3}\right)$ and filtration the reaction mixture was evaporated to dryness. The crude product was purified by chromatography on a silica gel column eluted with solvent $c$. The yield of chromatographically pure 3 was $260 \mathrm{mg}$. Part of 3 was acetylated and analyzed by GLC-MS. This analysis showed a single peak with a mass spectrum containing the ions $m / e \quad 43$ (71), 45 (28), 71 (13), 73 (9), 75 (12), 88 (100), 89(7), 101 (48:, $111(4), 155(2), 159(43), 160(3)$, 187 (5), $219(15)$.

1-O-(2,3,4,6-Tetra-O-methyl- $\beta$-D-glucosyl)-2-Omethyl-D,L-glycerol (4). 4 was obtained from 2 by (a) tritylation, (b) methylation and (c) detritylation.

(a) Tritylation. $2(200 \mathrm{mg})$ and chlorotriphenylmethane $(300 \mathrm{mg})$ were added to pyridine $(5 \mathrm{ml})$. The mixture was stirred at room temperature for $48 \mathrm{~h}$. After this time practically no starting material remained and a new major compound had been formed as a seen by TLC (solvent e). The reaction mixture was worked up as described above (under synthesis of 1). The crude product was purified by chromatography on silica gel column eluted with solvent e. Pure 1-O-(2,3,4,6-tetra- $O$-methyl- $\beta$-D-glucosyl)-3-O-trityl-D,L-glycerol was obtained as a syrup (330 mg).

(b) Methylation. 1-O-(2,3,4,6-Tetra- $O$-methyl- $\beta$ D-glucosyl)-3-O-trityl-D,L-glycerol $(300 \mathrm{mg}$ ) (above) was methylated as previously deviously described. ${ }^{13}$ The crude product was purified twice by chromatography on a silica gel column eluted with solvent e. Chromatographically pure $1-O-(2,3,4,6-$ tetra- $O$-methyl- $\beta$-D-glucosyl)-2- $O$-methyl-3- $O$-tritylD,L-glycerol was obtained as a syrup $(240 \mathrm{mg})$.

(c) Detritylation. 1-O-(2,3,4,6-Tetra- $O$-methyl- $\beta$ D-glucosyl)-2-O-methyl-3-O-trityl-D,L-glycerol (200 $\mathrm{mg}$ ) was detritylated by treatment with $0.2 \mathrm{M}$ hydrochloric acid in methanol $(40 \mathrm{ml})$ as described above (under synthesis of 1 ). The crude product was purified by chromatography on a silica gel column eluted with solvent $b$ to yield $4(100 \mathrm{mg})$ as a pure syrup. Part of 4 was acetylated and analyzed by GLC-MS giving a single peak with the ions $m / e 43$ (26), $25(28), 71(37), 73(11), 75(16), 88(100), 89(11)$, $101(68), 102$ (7), $111(6), 117(8), 127$ (5), 131 (95), 132 (6), $145(3), 155(2), 187$ (8), 191 (27), 192 (2).

2-Hydroxyethyl 2,3,4-tri-O-methyl- $\beta$-D-glucoside (5). 5 was obtained from $2-O$-trityloxyethyl $\beta$-Dglucopyranoside (see under preparation of 1 ) by (a) tritylation, (b) methylation and (c) detritylation.

(a) Tritylation. 2-O-Trityloxyethyl $\beta$-D-glucopyranoside $(250 \mathrm{mg})$ and chlorotriphenylmethane $(150 \mathrm{mg})$ were added to pyridine $(5 \mathrm{ml})$ and the mixture was stirred for $48 \mathrm{~h}$ at room temperature. After this time the reaction mixture was kept at $100{ }^{\circ} \mathrm{C}$ for $1 \mathrm{~h}$. After cooling the reaction mixture was worked up as previously described. The crude product (2- $O$-trityloxyethyl 6- $O$-trityl- $\beta$-D-glucopyranoside) was not purified further.

(b) Methylation. The crude 2-O-trityloxyethyl 6$O$-trityl- $\beta$-D-glucopyranoside (above) was methylated as previously described. ${ }^{12}$ The crude product (2-O-trityloxyethyl 2,3,4-tri- $O$-methyl-6- $O$-trityl- $\beta$ D-glucoside) was not isolated, but the residue after the work-up was used directly in the next step.

(c) Detritylation. The crude 2-O-trityloxyethyl 2,3,4-tri- $O$-methyl-6- $O$-trityl- $\beta$-D-glucoside (above) was treated with $0.2 \mathrm{M}$ hydrochloric acid in methanol-ethanol $(1: 1, \mathrm{v} / \mathrm{v})$ for $18 \mathrm{~h}$ at room temperature. After neutralization $\left(\mathrm{Ag}_{2} \mathrm{CO}_{3}\right)$ and filtration the reaction mixture was evaporated to dryness. The crude product was purified on a silica gel column eluted with solvent $\mathrm{c}$. The main component consisting of 5 was purified further as its peracetylated derivative on a silica gel column eluted with solvent $f$. The peracetylated 5 was obtained as a chromatographically pure syrup $(150 \mathrm{mg})$. Analysis of peracetylated 5, by GLC-MS, showed a single 
peak with a mass spectrum containing the ions $m / e 43$ (23), 45 (6), 73 (6), 75 (4), 87 (43), 88 (100), 89 (3), 101 (44), 147 (9), 155 (4), 215 (2).

The pure peracetylated $5(140 \mathrm{mg})$ was de- $O$ acetylated with $\mathbf{M}$ ammonia in methanol-water $(4: 1)(20 \mathrm{ml})$ as described above (see under synthesis of 1). The crude product was purified on a silica gel column, eluted with solvent $\mathrm{c}$, to yield chromatographically pure, amorphous $5(90 \mathrm{mg})$.

2-O-(2,3,4-Tri-O-methyl- $\beta$-D-glucosyl)-glycerol (6). 6 was obtained from $2-O-(\beta$-D-glucopyranosyl)1,3-O-benzylidene-glycerol (see under preparation of 3) by (a) tritylation, (b) methylation and (c) removal of $O$-trityl and $O$-benzylidene groups.

(a) Tritylation. 2-O-( $\beta$-D-Glucopyranosyl)-1,3-Obenzylidene-glycerol $(250 \mathrm{mg})$ and chlorotriphenylmethane $(220 \mathrm{mg})$ were added to pyridine $(5 \mathrm{ml})$ and the mixture was stirred for $48 \mathrm{~h}$ at room temperature. After this time the reaction mixture was heated for $1 \mathrm{~h}$ at $100{ }^{\circ} \mathrm{C}$. After cooling the reaction mixture was worked up as previously described. The crude product $2-O-(6-O$-trityl- $\beta$-Dglucopyranosyl)-1,3-O-benzylidene-glycerol was not purified further.

(b) Methylation. The crude 2-O-(6-O-trityl- $\beta-\mathrm{D}-$ D-glucopyranosyl)-1,3-O-benzylidene-glycerol

(above) was methylated as previously described. The crude product $2-O$-(2,3,4-tri- $O$-methyl-6- $O$-trityl- $\beta$ D-glycosyl)-1,3-O-benzylidene-glycerol was not isolated, but the residue after the work-up was used directly in the next step.

(c) Removal of O-trityl and O-benzylidene groups. The crude $2-O$-(2,3,4-tri- $O$-methyl-6- $O$-trityl- $\beta$-Dglucosyl)-1,3-O-benzylidene-glycerol was treated with $0.5 \mathrm{M}$ hydrochloric acid in methanol for $18 \mathrm{~h}$ at room temperature. After neutralization $\left(\mathrm{Ag}_{2} \mathrm{CO}_{3}\right)$ and filtration the reaction mixture was evaporated to dryness. The crude product was purified on a silica gel column eluted with solvent $d$. The main component consisting of 6 was purified further as its peracetylated derivative on a silica gel column eluted with solvent $a$. The peracetylated 6 was obtained as a chromatographically pure syrup (250 $\mathrm{mg}$ ). Analysis of peracetylated 6, by GLC-MS, showed a single peak with a mass spectrum containing the ions $m / e 42$ (13), 43 (19), 71 (10), 73 (6), 75 (5), 87 (8), 88 (100), $101(61), 127(6), 155(8)$, 159 (73), $160(9), 183(3), 215(3), 219(20)$. The pure peracetylated $6(240 \mathrm{mg})$ was de- $O$-acetylated with $M$ ammonia in methanol-water $(4: 1)(20 \mathrm{ml})$ as described above (see under synthesis of 1). The crude product was purified on a silica gel column eluted with solvent d, to yield chromatographically pure 6 as a syrup $(150 \mathrm{mg})$.

Trifluoroacetolysis experiments. Each of the compounds $1-6$, methyl $2,3,4,6$-tetra- $O$-methyl- $\beta$-Dglucoside ${ }^{16}$ and methyl 2,3,4-tri- $O$-methyl- $\beta$-D-glucoside $^{16}(25 \mathrm{mg})$ were dissolved together with methyl
$\alpha$-D-glucopyranoside (15 mg) (as stable internal standard $)^{7}$ in methanol $(5 \mathrm{ml})$. Part of the mixture $(1 \mathrm{ml})$ was acetylated and analyzed by GLC-MS after acetylation to obtain response factors for quantitative determinations. Other portions $(1 \mathrm{ml})$ were dried and dissolved in TFA - TFAA $(1: 1,1: 4$, and $1: 50, \mathrm{v} / \mathrm{v})(4 \mathrm{ml})$ and then heated in a sealed glass tube at $60^{\circ} \mathrm{C}$ or $100{ }^{\circ} \mathrm{C}$ for $48 \mathrm{~h}$. (Caution! Corrosive mixture under pressure.)

The mixtures were then cooled to room temperature and evaporated to dryness. The residues were dissolved in methanol $(2 \mathrm{ml})$ and the solutions were evaporated to dryness. The residues were then dissolved in ethanol-water $(2: 1, \mathrm{v} / \mathrm{v})(2 \mathrm{ml})$ and reduced with sodium borohydride $(10 \mathrm{mg})$ and acetylated. The components in the product were identified by GLC-MS in comparison with authentic materials.

Acknowledgements. The authors are inbedted to the Swedish Medical Research Council (O3X-4956), the Medical Faculty, University of Lund and Magnus Bergvall's Foundation for financial support.

\section{REFERENCES}

1. Nilsson, B. and Svensson, S. Carbohydr. Res. 62 (1978) 377.

2. Nilsson, B. and Svensson, S. Carbohydr. Res. 65 (1978) 169 .

3. Nilsson, B. and Svensson, S. Carbohydr. Res. 72 (1979) 183.

4. Nilsson, B., Nordén, N. E. and Svensson, S. J. Biol. Chem. 254 (1979) 4545.

5. Lindberg, B., Nilsson, B., Norberg, T. and Svensson, S. Acta Chem. Scand. B 33 (1979) 230.

6. Lundsten, J., Svensson, S. and Svennerholm, L. FEBS Lett. In press.

7. Nilsson, B. and Svensson, S. Carbohydr. Res. 69 (1979) 292.

8. Franzén, L.-E. and Svensson, S. Carbohydr. Res. 73 (1979) 309.

9. Franzén, L.-E. and Svensson, S. Carbohydr. Res. In press.

10. Kochetkov, N. K. and Chizhov, O. S. $A d v$. Carbohydr. Chem. 21 (1966) 39.

11. Fischer, E. and Fischer, H. Ber. Dtsch. Chem. Ges. 43 (1910) 2528.

12. Reynolds, D. D. and Evans, W. L. J. Am. Chem. Soc. 60 (1938) 2559.

13. Hakomori, S. J. Biochem. (Tokyo) 55 (1964) 205.

14. Karrer, P. and Hurwitz, O. Helv. Chim. Acta 5 (1922) 864.

15. Carter, N. M. Ber. Dtsch. Chem. Ges. 63 (1930) 1684.

16. BeMiller, J. N. Methods Carbohydr. Chem. 5 (1965) 298. 